\title{
CAPÍTULO 15 \\ OS FATORES E OS IMPACTOS AMBIENTAIS EM SOLOS PRAIANOS
}

\author{
Mário Marcos Moreira da Conceição ${ }^{\mathbf{1}} ;$.2. E-mail: mariomarcosmc.7@gmail.com \\ Ana Claudia de Sousa da Silva²; Ruana Regina Negrão de Souza ${ }^{2}$ \\ 1 - Autor para correspondência. \\ 2 - Universidade do Estado do Pará. Campus VI. Paragominas - PA. \\ DOI:10.4322/978-85-455202-0-7-15
}

\begin{abstract}
RESUMO
Nas últimas décadas do século XXI, as pressões sobre os ecossistemas têm aumentado sistematicamente em uma escala global. Um dos grandes desafios que está presente na sociedade moderna é o equacionamento da geração hiperbólica e da disposição final adequada dos resíduos sólidos, pois o gerenciamento inadequado e a falta de áreas para disposição final afetam diretamente os domicílios em função do crescimento da produção de resíduos. Neste contexto, o objetivo desta pesquisa é verificar as principais fontes da poluição do solo na praia de Atalaia, Salinópolis-PA. O método aplicado foi o dedutivo. Quanto a natureza, foi aplicada. Além disso a pesquisa foi observativa e sistemática. Foram efetuadas visitas in situ para coleta de dados, nos dias 25 e 26 de agosto, 26,27 e 28 de outubro de 2017, onde se investigou dentro de uma observação do local de estudo, os principais fatores de poluição/contaminação do solo. Os dados obtidos e analisados indicaram como um dos principais problemas a compactação do solo. Outro impacto ambiental identificado na área de pesquisa foi a erosão do solo que se apresenta como um processo mecânico e atua na superfície. A análise dos dados obtidos também indicou que a contaminação do solo está relacionada à disposição de substâncias químicas, tais como, óleos, graxas, e resíduos sólidos depositados de forma inadequada como: garrafas de alumínio, plásticas - pets, resíduos orgânicos, isopores, vidros, metais entre outros que afetam a qualidade da água e do meio de depósito. Dessa forma, a disposição final adequada dos resíduos sólidos deve ser informada à comunidade sazonal ou fixa, com o emprego da Educação Ambiental, a partir de ferramentas e técnicas adequadas.
\end{abstract}

PALAVRAS CHAVE: Ecossistemas. Poluição. Resíduos.

\begin{abstract}
In the last decades of the 21st century, pressures on ecosystems have systematically increased on a global scale. One of the great challenges that is present in modern society is the equation of the hyperbolic generation and the adequate final disposition of the solid residues, because inadequate management and lack of final disposal areas directly affect households because of increased waste production. In this context, the objective of this
\end{abstract}


research is to verify the main sources of soil pollution in the beach of atalaia, salinópolispa. The method applied was deductive. As for nature, it was applied. In addition, the research was observational and systematic. in situ visits were made for data collection, on august 25 and 26, 26,27 and 28 October 2017, where it was investigated within an observation of the study site the main factors of pollution / contamination of the soil. The data obtained and analyzed indicated as one of the main problems soil compaction. Another environmental impact identified in the research area was soil erosion that presents itself as a mechanical process and acts on the surface. The analysis of the data obtained also indicated that the contamination of the soil is related to the disposal of chemical substances, such as oils, greases, and improperly deposited solid wastes such as: aluminum bottles, plastic - pets, organic waste, Styrofoam, glass, metals, among others that affect the quality of the water and the storage medium. In this way, the final disposal of solid waste they be informed to the seasonal or fixed community, using Environmental Education, using appropriate tools and techniques.

KEY WORDS: Ecosystems. Pollution. Waste.

\section{INTRODUÇÃO}

Nas últimas décadas do século XXI, as pressões sobre os ecossistemas têm aumentado sistematicamente em uma escala global. Estes vêm se exaurindo e ameaçando a capacidade de suporte dos serviços providos pelos mesmos às atividades humanas. Desta forma, a Organização Mundial da Saúde - OMS, tem realizado alertas quanto a utilização não sustentável dos ecossistemas. Este uso ineficiente eleva o potencial de mudanças ecológicas para um quadro grave e irreversível, o que torna imprescindível uma sensibilização da sociedade para minimizar os problemas relacionados a saúde ambiental (SILVEIRA; ARAUJO NETO, 2014).

Neste contexto, A Política Nacional de Resíduos Sólidos - PNRS, criada pela Lei $\mathrm{n}^{\mathrm{o}} 12.305$, de 2010 e regulamentada pelo Decreto $\mathrm{n}^{\mathrm{o}} 7.404$, de 2010 , criou como um dos seus principais instrumentos o Plano Nacional de Resíduos Sólidos. Neste plano a estimativa da composição gravimétrica dos resíduos sólidos urbanos coletados no Brasil em 2008 era de 183.481,50 toneladas/dia. No mesmo ano, a taxa de produção em $\mathrm{Kg} /$ hab.dia foi de 1,3 na região norte, superior a região sudeste e sul. A falta de locais estratégicos para direcioná-los como cestos coletores residuais é um fator que propicia a degradação de ecossistemas como os aquáticos (BRASIL, 2010).

Tal entrave é decorrente principalmente da criação de embalagens e produtos descartáveis, pela facilidade de fabricação e uso, assim como da disposição final inadequada desses materiais que ficam por décadas no meio ambiente como: pneus, latas, sacolas plásticas, matéria orgânica, entre outros elementos que contaminam principalmente a água o ar e o solo (SILVA; ZAIDAN, 2012 grifo nosso).

Um dos grandes desafios que está presente na sociedade moderna é o equacionamento da geração hiperbólica e da disposição final adequada dos resíduos 
sólidos, pois o gerenciamento inadequado e a falta de áreas para disposição final afetam diretamente os domicílios em função do crescimento da produção de resíduos (JACOBI; BESEN, 2011).

Além disso, o fluxo de turistas para o litoral tem provocado uma ocupação desordenada dos sítios litorâneos, devido a uma ocupação extensiva do espaço, com implantação de infraestruturas viária, comercial e de lazer, frequentemente avançando para o mar, com isso, as paisagens urbanas têm sido modificadas, através da implantação de projetos urbanos que divulguem imagens favoráveis para a atividade turística, o que propicia impactos ambientais. No estado do Pará, em particular nas cidades litorâneas, a valorização das cidades vem sendo associada ao acelerado processo de urbanização, voltado para o incentivo da atividade turística e construção da imagem (BOMFIM; SILVA, 2009; SOUZA, 2014).

Diante desta perspectiva, tal pesquisa justifica-se pelo aumento da expansão urbana desordenada, e ao aumento de ações antrópicas inadequadas que alteram principalmente a qualidade das águas locais, como: despejo de esgotos domésticos, resíduos sólidos, óleos de veículos, entre outros agravantes de problemas socioambientais. Neste contexto, o objetivo desta pesquisa é verificar as principais fontes da poluição do solo na praia de Atalaia, Salinópolis-PA.

\section{METODOLOGIA}

O estudo foi realizado no município de Salinópolis-PA (Figura 1), localizada na mesorregião nordeste paraense, distante aproximadamente $220 \mathrm{~km}$ de Belém do Pará, capital do estado. Apresenta as coordenadas: $00^{\circ} 30^{\prime}$ e $01^{\circ} 00^{\prime}$ de latitude Sul e $47^{\circ} 00^{\prime}$ e $47^{\circ} 30^{\prime}$ de longitude, e uma área aproximada de $217.856 \mathrm{~km}^{2}$, população estimada em 39.328 habitantes, obtendo como resultado uma densidade demográfica de 157,4 habitantes por $\mathrm{km}^{2}$. O município possui várias características naturais, principalmente a presença de praias de águas salgadas, como a do Maçarico e Atalaia que estimula o turismo local (IBGE, 2017).

A praia do Atalaia está localizada ao extremo leste de Salinópolis (Figura 1), é limitada por dunas frontais e permanentes cobertas com vegetação de restinga e em parte por moradias construídas no pós-praia. Fatores que contribuem para a ocupação desorganizada dessa área ocasionaram impactos socioambientais como a ação de processos naturais, e as atividades antrópica com maior intensidade, principalmente a partir da construção da rodovia PA-444 Salinópolis-Atalaia (RANIERI; EL-ROBRINI, 2015). 
Figura 1 - Cartografia com de localização da área de estudo. Salinópolis-PA.

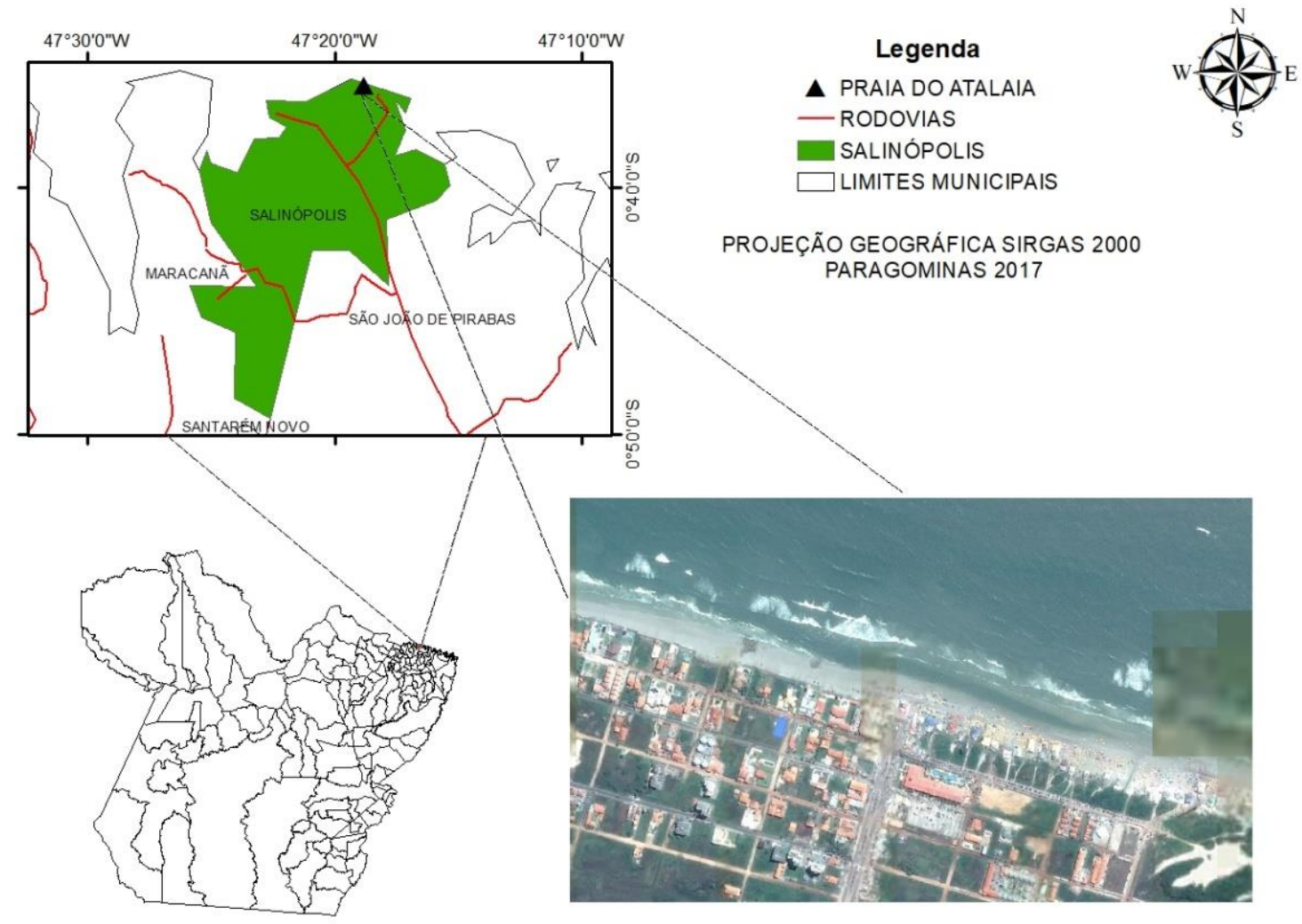

Fonte: Google Earth (2017)

No contexto municipal, Salinópolis-PA, passou a ser considerado um dos principais balneários paraenses, onde muitos visitantes possuem casa de segunda residência, além disso, atrai visitantes de outras regiões do país. Com isso, o processo de urbanização possibilitou a substituição de áreas naturais por áreas urbanas, ocasionando um rastro enorme de degradação ambiental. Tal fator é responsável pelo aumento da expansão urbana desordenada sobre os limites da costa, e ao aumento de ações antrópicas inadequadas que comprometem principalmente a qualidade das águas, como: despejo de esgotos domésticos, resíduos sólidos, óleos de veículos, entre outros agravantes de problemas à saúde ambiental e consequentemente a saúde da comunidade (CARVALHO, et al 2010). (CARVALHO, et al 2010).

Salinópolis apresenta urbanização mais densa próxima aos limites da praia. É o único município onde se observa edificações prediais sobre as áreas próximas à linha de costa. Cerca de $50 \%$ da faixa de praias oceânicas de Salinópolis é limitada por zona urbanizada e a outra metade ainda se apresenta conservada. A interferência com o meio físico, principalmente no que se relaciona com a dinâmica dos processos sedimentares, é induzida, em grande parte, por ações de natureza antrópica, podendo acarretar problemas no âmbito ambiental. Do ponto de vista ambiental, as principais alterações são na linha da costa, decorrente de erosões, assoreamento e entre outros impactos. A ocupação do 
ambiente praial por casas, edificações ou outras estruturas modifica o equilíbrio sedimentar natural das praias (RANIERI; EL-ROBRINI, 2016).

O método aplicado foi o dedutivo, pois, com tal processo de raciocínio é possível, partindo de uma ou mais premissas a obtenção de uma conclusão imprescindível e evidente. Em relação aos procedimentos, foi a partir de pesquisa-ação. Quanto a natureza, foi aplicada, pois objetiva gerar conhecimentos para aplicação prática, dirigidos à solução de problemas específicos. Envolve verdades e interesses locais (GERHARDT; SILVEIRA, 2009; MATIAS-PEREIRA, 2016). Além disso a pesquisa foi observativa e sistemática (Figura 2). Em relação à abordagem, esta pesquisa teve característica qualitativa, pois, buscam explicar o porquê das coisas e sua origem, relações e mudanças, e tenta intuir as consequências, de forma a adquirir uma compreensão detalhada dos significados e características situacionais (OLIVEIRA, 2011).

Figura 2 - Aplicação da metodologia avaliativa para possibilitar posicionamento crítico/avaliativo.

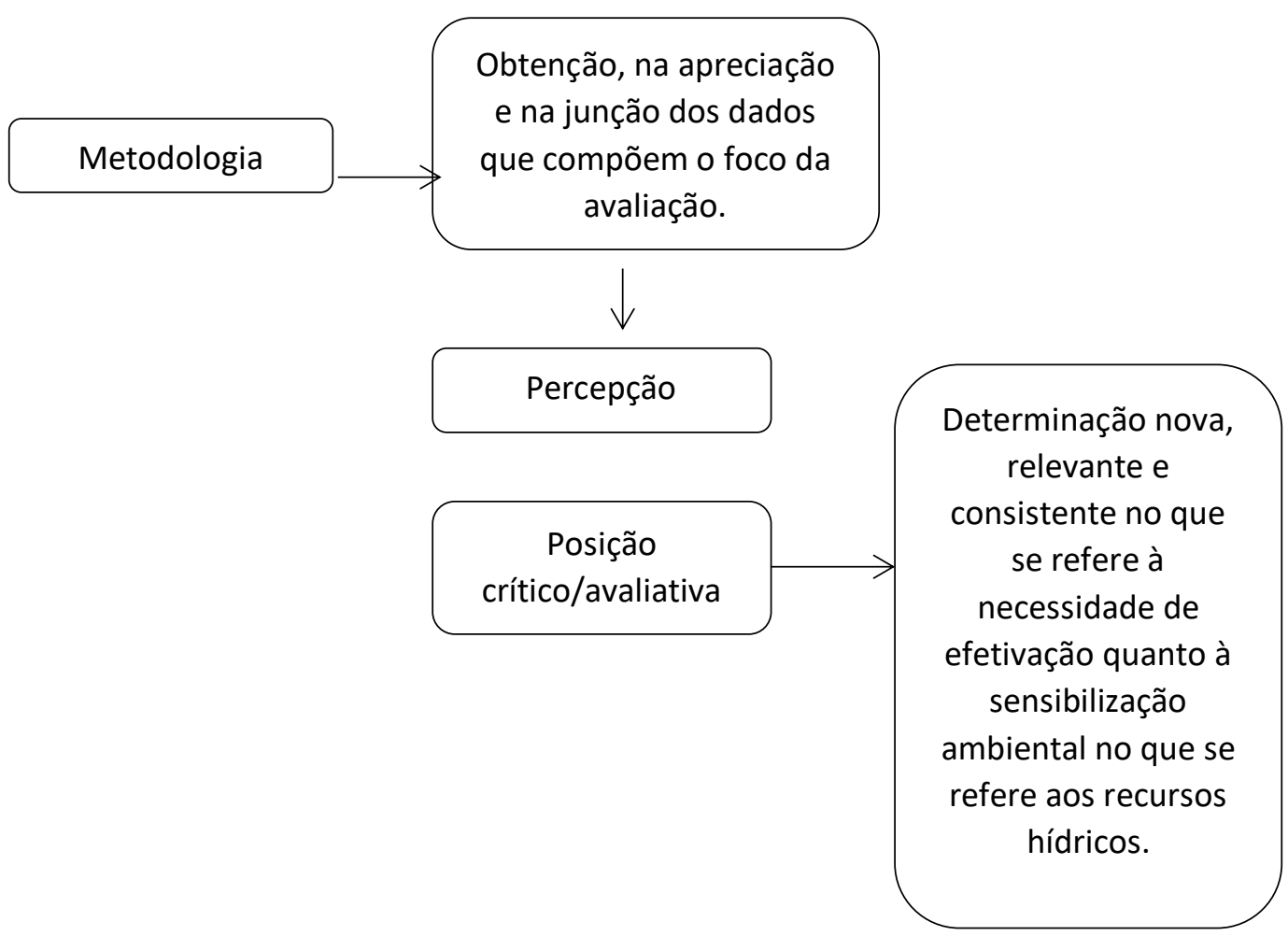

Fonte: autores (2017)

Posteriormente, foram efetuadas visitas in situ para coleta de dados, nos dias 25 e 26 de agosto, 26,27 e 28 de outubro de 2017, onde se investigou dentro de uma observação do local de estudo, os principais fatores de poluição/contaminação do solo. Posteriormente obtiveram-se arquivos fotográficos do local de estudo que serviram como fonte secundária para auxiliar na construção das informações subjetivas, além de servirem como parâmetros evidentes para estudo descritivo do local. 


\section{DISCUSSÕES}

A análise dos dados obtidos indicou que a poluição do solo se dá principalmente pelo gerenciamento inadequado dos resíduos e rejeitos produzidos pelos turistas e vendedores autônomos do local como, por exemplo, cascas de coco, garrafas PET, latas de alumínio, etc. Este entrave altera as características naturais do meio, como no índice de acidez do solo pela decomposição desses materiais. Tais resíduos são produzidos diariamente e nem sempre são direcionados para locais apropriados, e ficam exposto no solo, o que facilita o arraste, durante o período das cheias das mares, por águas superficiais e contamina o meio ambiente.

O estudo realizado por Carvalho (2010) em Vitória da Conquista - BA concluiu a sociedade tem grande influência na qualidade do meio utilizado, pois, se esta população que utiliza este recurso natural não for sensibilizada dos malefícios que o descarte de materiais como os orgânicos causam ao meio, como elevação da acidez no solo, podem acarretar problemas graves ao meio ambiente.

Os dados obtidos e analisados indicaram que, além dos danos causados diretamente ao solo pelo depósito de lixo, os riscos Iminentes à saúde dos turistas são decorrentes principalmente de materiais perfuro-cortantes, como, por exemplo, garrafas de vidro já estilhaçadas, ou resíduos orgânicos cuja decomposição pode atrair vetores de doenças (Ex.: Ratus novergicus) como a leptospirose, o que os torna vulneráveis a tais problemas.

Ranieri e El-Robrini (2015), realização uma pesquisa sobre impactos ambientais em Salinópolis - PA, e indicaram que as principais alterações são na linha do litoral, decorrente de erosões e assoreamento, que são intensificados pelo acúmulo de resíduos no solo. Outro fator que acelera esses processos são a ocupação do ambiente praial por casas, edificações ou outras estruturas modifica o equilíbrio sedimentar natural das praias.

Em relação a compactação do solo, a análise dos dados obtidos indicou esse é um dos impactos ambientais mais perceptíveis no local. Tal problemática é advinda do processo de tráfego dos veículos na área pesquisada (Figura 3) de carros e ônibus que passam constantemente pelo local e, com isso, provocam a compactação do solo, consequentemente, interferem indiretamente na recarga dos corpos hídricos da região. 
Figura 3 - Área compactada por tráfego de veículos. Salinas - PA.

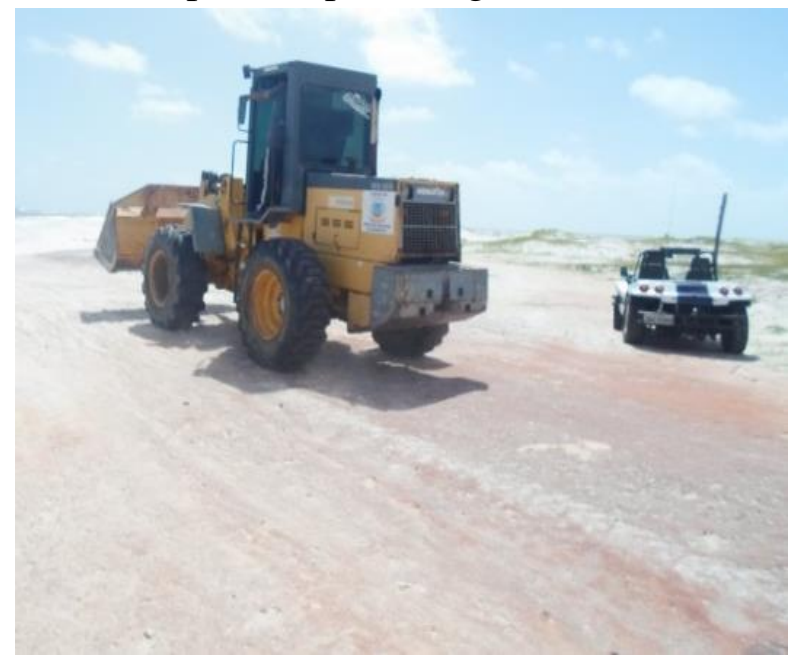

Fonte: autores (2017).

Outro estudo, agora efetuado em Gurupi - TO, por Souza et al. (2016), concluiu que os problemas de erosão e de compactação do solo pelo tráfego de veículos e a sua exposição a processos erosivos, como pela perda da cobertura vegetal, impermeabilização, compactação e desestruturação do solo, esses processos podem acarretar o arraste das partículas de solo desagregadas, através do escoamento superficial das águas pluviais que podem depositar-se nos canais de drenagem ou nos cursos d'água.

No estado de Minas Gerais, Figueiredo et al. (2010) efetuaram um estudo sobre a porosidade do solo, e concluíram que ela é um dos indicadores físicos mais importantes e mais frequentes sobre a qualidade do solo, pois, expressa o grau de compactação e o quanto as atividades antrópicas impactam este meio. Neste contexto, o tráfego de veículos contribui para a deformidade da porosidade do solo e ocasiona a perda da porosidade através do adensamento de suas partículas.

Outro impacto ambiental identificado na área de pesquisa foi a erosão do solo que se apresenta como um processo mecânico e atua na superfície e em profundidade, podendo ocorrer em determinados tipos de solos e condições físicas (Figura 4).

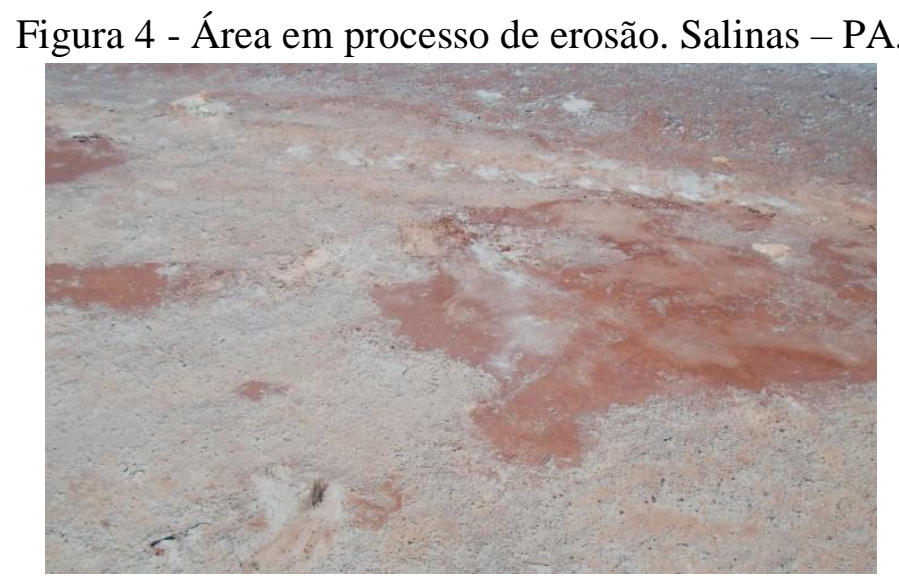

Fonte: autores (2017) 
De acordo com estudo efetuado por Telles et al. (2013), o autor concluiu que este fenômeno se manifesta como uma consequência da quebra de equilíbrio do meio ambiente, precedido pela mudança da paisagem, oriunda da eliminação da cobertura vegetal para a iniciação de novos usos do solo, o que possibilita o assoreamento, acelera o processo de erosão do solo e alteram suas características físico-químicas.

A análise dos dados obtidos também indicou que a contaminação do solo está relacionada à disposição de substâncias químicas, tais como, óleos, graxas, e resíduos sólidos depositados de forma inadequada como: garrafas de alumínio, plásticas - pets, resíduos orgânicos, isopores, vidros, metais entre outros que afetam a qualidade da água e do meio de depósito (Figuras 5a e 5b).

Figura 5 - a) Resíduos sólidos acumulados na praia do Atalaia; b) Áreas com acúmulo de resíduos sólidos diversos em estado de decomposição. Salinas - PA.

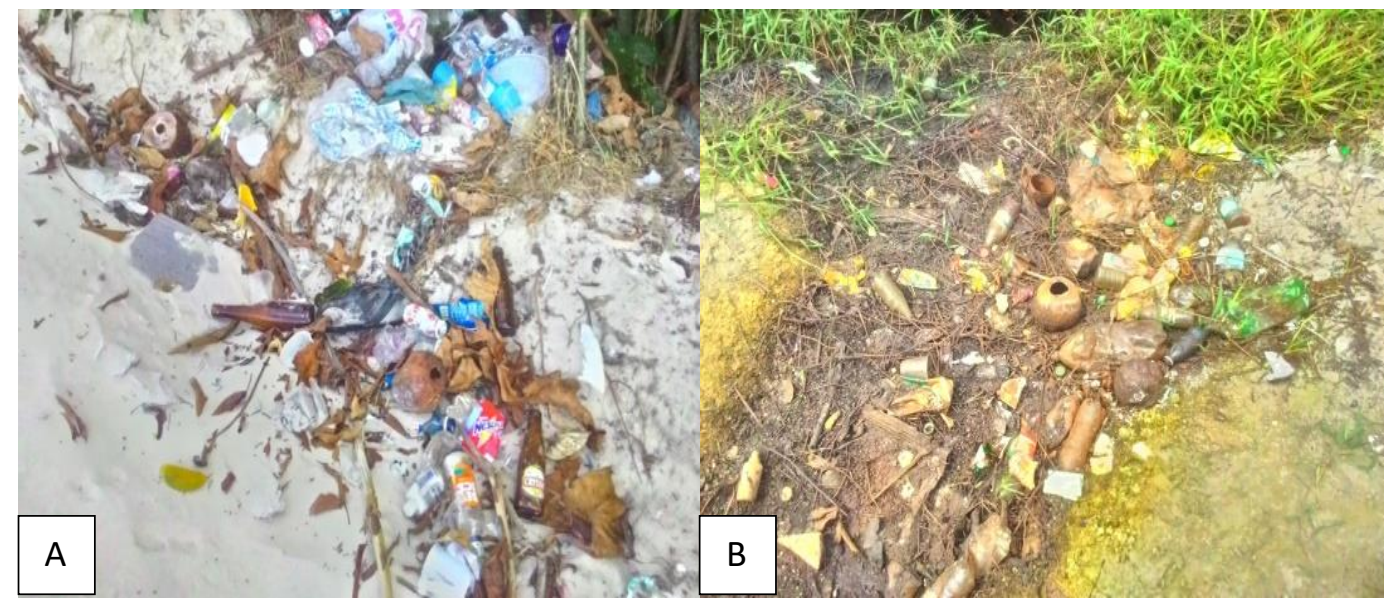

Fonte: autores (2017).

Com isso, tais fatores tronam-se um impacto direto potencial, o qual além de contaminar o solo pode também atingir os corpos hídricos superficiais. Dessa forma, existe a necessidade de um maior envolvimento dos órgãos responsáveis pela fiscalização como a SEMA municipal, não apenas referente à disposição final adequada dos resíduos sólidos, mas sobre meios que promovam a sensibilização sociedade com ações como: alocação de cartazes sobre educação ambiental e projetos de participação social que intensifique a fomentação de atitudes de preservação sobre o meio ambiente por parte da comunidade local e turística, pois, tais substâncias, além de contaminar o solo, podem atingir os corpos hídricos superficiais.

\section{CONSIDERAÇÕES FINAIS}

As principais fontes da poluição do solo na praia de Atalaia, Salinópolis-PA, é decorrente do despejo inadequado dos resíduos e rejeitos gerados por turistas e 
comerciantes do local, cuja destinação e disposição final são inadequados. O tráfego de veículos causa problemas estruturais ao solo como a compactação e processos erosivos. As atividades domésticas, comerciais ou industriais, geram implicações que diretamente ou indiretamente degradam este recurso natural e por ações que comprometam a qualidade do local como a expansão urbana desordenada.

Dessa forma, a disposição final adequada dos resíduos sólidos deve ser informada à comunidade sazonal ou fixa, com o emprego da Educação Ambiental, a partir de ferramentas e técnicas adequadas como, por exemplo, alocação de cartazes e meios que promovam a sensibilização ambiental da comunidade envolvida, como sobre educação ambiental e projetos de participação social que intensifique a fomentação de atitudes de preservação sobre o meio ambiente possibilitará melhor qualidade de vida a comunidade e dos recursos ambientais.

\section{REFERÊNCIAS}

ANACHE, J. A. A. et al. Assessment Of Methods For Predicting Soil Erodibility In Soil Loss Modeling. Revista Geociências. São Paulo, v. 34, n. 1, p.32-40, set. 2015.

BOMFIM, A. R.; SILVA JÚNIOR J. F. G. Diagnóstico do gerenciamento de resíduos sólidos urbanos em Porto Seguro - BA. Enciclopédia Biosfera. Goiânia, v. 5, n. 8, p.17, jul. 2009.

CARVALHO, J. P. V. et al. Os efeitos da degradação dos recursos hídricos nos espaços urbanos de Vitória da Conquista - BA. Enciclopédia Biosfera. Goiânia, v. 6, n. 10, p.19, jun. 2010.

FIGUEIREDO, M. A. et al. Compactação do Solo como Indicador Pedogeomorfológico Para Erosão em Trilhas de Unidades de Conservação: estudo de caso no parque nacional da serra do cipó, MG. Revista de Geografia. Recife, v. 1, n. 3, p.236-247, set. 2010.

GERHARDT, T. E.; SILVEIRA, D. T. Métodos de pesquisa. Porto Alegre: UFRGS, 2009. 114 p.

IBGE. INSTITUTO BRASILEIRO DE GEOGRAFIA E ESTATÍSTICA. Cidades. Salinópolis-PA. Disponível em:< http://cidades.ibge.gov.br/xtras/temas.php?lang=\&codmun=150620\&idtema=16\&searc $\mathrm{h}=$ para|salinopolis|sintese-das-informacoes > Acesso em: 27 ago. 2017.

JACOBI, P. R.; BESEN, G. R. Gestão de resíduos sólidos em São Paulo: desafios da sustentabilidade. Estudos Avançados. São Paulo, v. 71, n. 25, abr. 2011.

OLIVEIRA, M. F. Metodologia científica: manual para a realização de pesquisas em Administração. Goiás: Catalão, 2011. 72 p. 
RANIERI, L. A.; EL-ROBRINI, M. Evolução da linha de costa de Salinópolis, Nordeste do Pará, Brasil. Pesquisas em Geociência. Porto Alegre, v. 3, n. 42, p.207-226, dez. 2015.

SANDOVAL, M. S; CERRI, L. E. S. Proposta de Padronização de Avaliação de Impactos Ambientais. Engenharia Ambiental. Espírito Santo do Pinhal, v. 6, n. 2, p.100-113, ago. 2009.

SANTOS, J. C. N. et al. Land use impact on soil erosion at different scales in the Brazilian semi-arid. Revista Ciência Agronômica. Fortaleza, v. 48, n. 2, p.251-260, jul. 2017.

SANTOS, M. R.; VARELA, S. A Avaliação como um Instrumento Diagnóstico da Construção do Conhecimento Nas Séries Iniciais do Ensino Fundamental. Revista Eletrônica de Educação, Filadélfia, v. 1, n. 1, p.01-14, dez. 2008.

SILVA, F. R. Avaliação Ambiental Estratégica como Instrumento de Promoção do Desenvolvimento Sustentável. Direitos Fundamentais \& Democracia, Curitiba, v. 8, n. 8, p.301-329, jul-dez. 2010.

SILVA, J. X.; ZAIDAN, R. T. Geoprocessamento e Análise Ambiental: Aplicações. $6^{\circ}$ ed. Rio de Janeiro: Bertrand Brasil, 2012. p. 120.

SILVEIRA, M.; ARAUJO NETO, M. D. Licenciamento ambiental de grandes empreendimentos: conexão possível entre saúde e meio ambiente. Ciência \& Saúde Coletiva, Brasília, v. 19, n. 9, p.3829-3838, set. 2014.

SOUZA, D.L. Urbanização turística, políticas públicas e desenvolvimento: o caso de Salinópolis/PA. Geografia em questão. Paraná, v 07, n. 01, p. 65-86, jan-jul. 2014.

SOUZA, P. A. et al. Metodologias de Avaliação de Impactos Ambientais da APP, Rancho Tutty Falcão Gurupi -TO. Enciclopédia Biosfera. Goiânia, v. 13, n. 24, p.704-714, dez. 2016.

TELLES, T. S. et al. Valuation And Assessment Of Soil Erosion Costs. Scientia Agricola, São Paulo, v. 70, n. 3, p.209-216, mai. 2013. 